\title{
EDITORIAL NOTE Alzheimer's disease, the potential use of a bacterium in rice production, and the paleochannels of the Marajó Island
}

The recently published impact factor (ISI-Thomson 2007, 0.895) of the Anais da Academia Brasileira de Ciências (AABC) is significantly higher than the previous one and clearly shows that the importance of this scientific journal is gradually increasing. There is a great effort to attract more and more relevant papers and to expand the contribution of this periodical in the development of science worldwide.

This issue of the AABC presents a study related to Alzheimer's disease, one of the most investigated illnesses that affects a large percentage of elderly people. Among the treatments for this disease is the use of acetylcholinesterase inhibitors (AChEI). Recent studies have indicated that species of the plant Tabernaemontana might be a promising source of novel anticholinesterasic indole alkaloids. Ivo J.C. Vieira of the Universidade Estadual do Norte Fluminense (UENF) and colleagues obtained several alkaloids from Tabernaemontana laeta and Tabernaemontana hystrix and were able to identify novel cholinesterase inhibitors (ChEI) more easily by combining two fast screening methods.

Another interesting study might provide new ways to increase the productivity of rice. Katherine A. Mattos of the Instituto de Biofísica Carlos Chagas Filho (UFRJ) and co-workers have studied the capacity of the bacterium Burkholderia kururiensis to endophytically colonize rice plantlets. They monitored different tissues of root-inoculated samples by electron microscopy and 16S rDNA analysis and established a possible pathway for this bacterium to reach the aerial parts of the plant. This study concludes that Burkholderia kururiensis can foster plant growth and, consequently, higher production of rice.

A very different topic is focused by Dilce F. Rossetti of the Instituto Nacional de Pesquisas Espaciais (INPE) and Ana M. Góes of the Universidade de São Paulo (USP): the former drainage system of the Marajó Island. While in the eastern part the paleodrainage system could be easily mapped, little information was available from the western portion due to its dense vegetation. By combining remote sensing and sedimentological studies, those authors were able to identify the paleodrainage network in the region of the town Breves, southwestern Marajó Island. This whole drainage system differs from the modern one and was abandoned during the Late Pleistocene possibly due to tectonic activity related to the opening of the Pará river.

Alexander W.A. Kellner

Editor-in-chief 